\title{
Inhibition of cyclooxygenase-2 suppresses the invasiveness of oral squamous cell carcinoma cell lines via down-regulation of matrix metalloproteinase- 2 production and activation
}

\author{
Yuji Kurihara $\cdot$ Masashi Hatori $\cdot$ Yuriko Ando • \\ Daisuke Ito $\cdot$ Takahiko Toyoshima $\cdot$ Makoto Tanaka • \\ Satoru Shintani
}

Received: 21 January 2008/ Accepted: 22 January 2009/Published online: 25 February 2009

(C) The Author(s) 2009. This article is published with open access at Springerlink.com

\begin{abstract}
Increased cyclooxygenase (COX-2) expression in tumors is known to be correlated with tumor invasion, angiogenesis, resistance to apoptosis, and suppression of host immunity. We previously reported that the invasiveness of human oral squamous cell carcinoma (OSCC) cell lines NA and HSC-4 was suppressed by treatment with either NS-398, a selective COX-2 inhibitor, or COX-2 antisense oligonucleotide (AS). In the present study, to explore the effects of COX-2 inhibition on the interaction between cancer cells and fibroblasts, we examined the effects of these anti-COX-2 reagents on the expression of matrix metalloproteinases (MMPs) in fibroblast cell lines WI-38 and MRC-5. Western blotting and enzyme-linked immunosorbent assay revealed that NS-398 and COX-2 AS down-regulated the expression and secretion of MMP-2 and the tissue inhibitor of matrix metalloproteinase-2 (TIMP-2) in human fibroblast cell lines. Furthermore, invasion activity of OSCC cells was down-regulated by the addition of culture supernatant from fibroblasts treated with anti-COX-2 reagents in a Matrigel ${ }^{\circledR}$ invasion assay. These results suggest that selective COX-2 inhibition suppresses the invasion activity of OSCC cells via down-regulation of an MMP-2-activating mechanism involving TIMP-2 and production of the MMP-2 protein by an interaction between cancer cells and stromal fibroblasts. Genetic or pharmacological inhibition of COX-2 may therefore be a beneficial strategy in the treatment of OSCC.
\end{abstract}

Y. Kurihara $(\square) \cdot$ M. Hatori · Y. Ando · D. Ito ·

T. Toyoshima $\cdot$ M. Tanaka $\cdot$ S. Shintani

Department of Oral and Maxillofacial Surgery, School

of Dentistry, Showa University, 2-1-1 Kitasenzoku, Ota-ku,

Tokyo 145-8515, Japan

e-mail: yujikuri@senzoku.showa-u.ac.jp
Keywords COX-2 $\cdot$ MMP-2 - Squamous cell carcinoma . TIMP-2

\section{Introduction}

Arachidonic acid metabolites, collectively referred to as eicosanoids, include hydroxyeicosatetraenoic acids, prostaglandins (PGs), thromboxanes (TXs), and leucotrienes (LTs), and affect a number of signal transduction pathways that modulate the growth and differentiation of various cancer cell lines [1-3]. Cyclooxygenase (COX) is the ratelimiting enzyme for the production of PGs and TXs from free arachidonic acid [4]. Two forms of COX have been described: a constitutive enzyme (COX-1) present in most cells and tissues and an inducible isoenzyme (COX-2) expressed in response to cytokines, growth factors, and other stimuli [5]. It is reported that more than $80 \%$ of human colon cancers exhibit increased COX-2 levels when compared with adjacent normal tissue [6]. As well as in colorectal cancer, increased COX-2 expression has been confirmed in carcinomas of various organs, including the prostate, lung, esophagus, pancreas, and mucous membranes of the head and neck [7-11]. Previous studies have also demonstrated that the overexpression of COX-2 plays an important role in angiogenesis, resistance to apoptosis, and suppression of host immunity [12, 13]. Thus, it is conceivable that targeted inhibition of abnormally or improperly elevated COX-2 provides one of the most effective and promising strategies for cancer therapy. We previously reported that NS-398, a selective inhibitor of COX-2, and COX-2 antisense oligonucleotide (COX-2 AS) suppressed the proliferation and invasiveness of OSCC cell lines NA and HSC-4. These reagents also down-regulated the secretion of matrix metalloproteinase-2 (MMP-2) into 
culture supernatant as well as the expression of MMP-2 mRNA and protein. In addition, the expression of MT1-MMP, which activates proMMP-2 at the cell surface, leading to enhanced cellular invasion in vitro [14], was also down-regulated by treatment with these reagents $[15,16]$. However, MMP-2 is chiefly secreted from stromal cells and it is known to contribute to the acquisition of invasiveness by the cancer cells through activation of a tumorstromal interaction. Furthermore, tissue inhibitor of metalloproteinases (TIMP)-2 secreted from fibroblasts and MT1-MMP expressed on the surface of cancer cells are involved in this activation mechanism of MMP-2. The aim of this study was therefore to evaluate the effects of specific inhibition of COX-2, either by NS-398 or transfection with COX-2 antisense oligonucleotide, on the invasion activity of OSCC cells through tumor-stromal interaction.

\section{Materials and methods}

\section{Reagents}

NS-398, a selective inhibitor of COX-2, was purchased from Calbiochem-Novabiochem (San Diego, CA, USA). According to the manufacturer's information, NS-398 at $79.5 \mu \mathrm{M}$ selectively inhibits COX-2 activity without inhibiting COX-1 activity. Therefore, NS-398 at $79.5 \mu \mathrm{M}$ was used in the present study. Isogen, a reagent for extraction of total RNA, was obtained from Wako (Tokyo, Japan). As a primary antibody for Western blot analysis, MMP-2 monoclonal antibody (mouse anti-matrix metalloproteinase-2 aminoterminal end affinity isolated antibody) and TIMP-2 monoclonal antibody were purchased from Daiichi Fine Chemical (Toyama, Japan). Carboxy fluorescein (CFS)-conjugated mouse anti-human MMP-14 (MT1MMP) monoclonal antibody was purchased from Dako Corporation (Carpinteria, CA, USA). Horseradish peroxidase (HRP)-conjugated rabbit anti-Ig secondary antibody for Western blot analysis was purchased from Amersham Biosciences (Uppsala, Sweden).

\section{Cell lines and cell culture}

The NA and HSC-4 cancer cell lines established from patients with squamous cell carcinoma of the tongue were maintained as monolayers in Dulbecco's modified Eagle's medium (DMEM) supplemented with $10 \%$ heat-inactivated fetal bovine serum, 100 units $/ \mathrm{ml}$ penicillin, and $100 \mathrm{mg} / \mathrm{ml}$ streptomycin (complete medium). WI-38 and MRC-5 fibroblast cell lines were maintained in modified Eagle's medium (MEM) supplemented with $10 \%$ heat-inactivated fetal bovine serum, 100 units/ml penicillin, and $100 \mathrm{mg} / \mathrm{ml}$ streptomycin (complete medium). Subconfluent monolayers of these cells were used in all experiments. The culture supernatants of fibroblast cell lines were used as a chemoattractant for OSCC cells in an invasion assay.

Phosphorothioate antisense oligonucleotides

The phosphorothioate oligonucleotides used in this study were as follows: the COX-2 antisense oligonucleotide was 5'-GGAAACATCGACAGT-3' and the control (non-sense) oligonucleotide was $5^{\prime}$-TGCACTCACGCTCGG-3'. The scrape-loading delivery method was used to introduce oligonucleotides into the cytosol.

\section{MTT assay}

To assess the effects of either NS-398 or COX-2 AS on fibroblast cells, we performed an MTT assay. Briefly, fibroblast cells $\left(1 \times 10^{4}\right.$ cells per well $)$ were grown in 96-well plates (Falcon Labware, Oxnard, CA, USA) in the presence or absence of either $79.5 \mu \mathrm{M}$ of NS-398 or $5 \mu \mathrm{M}$ of COX-2 AS. After the appropriate incubation periods, $10 \mu \mathrm{l}$ of $5 \mathrm{mg} / \mathrm{ml} 3$-(4,5-dimethylthiazol-2-yl)-2,5-diphenyl tetrazolium bromide (MTT) was added to each well and then incubated for $4 \mathrm{~h}$. The reaction was terminated by the addition of $100 \mu \mathrm{l}$ of a solution of $0.04 \mathrm{~N} \mathrm{HCl}$ in isopropanol and the absorbance was measured with a Microtiter ${ }^{\circledR}$ Plate Reader MRX (DYNEX, Chantilly, VA, USA) at $595 \mathrm{~nm}$ with a reference wavelength of $630 \mathrm{~nm}$. All assays were run in triplicate.

\section{Western blot analysis}

Cells were plated in $10 \mathrm{ml}$ of complete medium containing $2 \times 10^{6}$ cells. After $18 \mathrm{~h}$ incubation, $79.5 \mu \mathrm{M}$ of NS-398 or $5 \mu \mathrm{M}$ of COX-2 AS was added to the culture. After a further $12 \mathrm{~h}$ incubation, cells were lysed in IGEPAL lysis buffer [20 mM HEPES ( $\mathrm{pH} 7.5$ ), $350 \mathrm{mM} \mathrm{NaCl}, 25 \%$ glycerol, $0.25 \%$ IGEPAL CA-630, $1 \mathrm{mM}$ sodium $o$-vanadate] with complete Mini ${ }^{\mathrm{TM}}$ protease inhibitor (Roche Diagnostics, Mannheim, Germany). Lysates were centrifuged at $14000 \times \mathrm{g}$ for $15 \mathrm{~min}$ at $4^{\circ} \mathrm{C}$ and their protein concentrations were measured by Bradford assay. Protein $(30 \mu \mathrm{g})$ was separated by SDS-PAGE, transferred to Hybond $^{\mathrm{TM}}$ PVDF membranes (Amersham Pharmacia Biotech, Buckinghamshire, UK), and after blocking by incubation for $90 \mathrm{~min}$ in $5 \%$ skim milk buffer at room temperature, the membranes were treated with the primary antibody (anti-MMP-2 and anti-TIMP-2 monoclonal antibody) followed by the HRP-conjugated secondary antibody (mouse anti-Ig antibody). Protein bands were visualized with the ECL plus ${ }^{\text {TM }}$ Western blot detection system (Amersham Pharmacia Biotech), according to the manufacturer's instructions. 
Invasion assay

The membrane invasion assay was performed in Matrigel $^{\circledR}$-coated invasion chambers (Becton Dickinson Labware, Franklin Lakes, NJ). Briefly, fibroblasts (WI-38 and MRC-5) were treated with $79.5 \mu \mathrm{M}$ of NS-398 or $5 \mu \mathrm{M}$ of COX-2 AS for $24 \mathrm{~h}$; the culture supernatant was replaced with fresh medium and the cells were further incubated for $24 \mathrm{~h}$. The culture supernatant of these fibroblasts was then placed in the upper chamber with $5 \times 10^{4}$ of OSCC cells and DMEM was placed in the lower chamber. Following $18 \mathrm{~h}$ of incubation at $37^{\circ} \mathrm{C}$ in a humidified $5 \% \mathrm{CO}_{2}$ atmosphere, cells in the upper chamber and on the Matrigel basement membrane matrix were mechanically removed with a cotton swab. Cells adherent to the outer surface of the membrane were fixed in $25 \%$ methanol and stained with crystal violet. The invading cells were counted and photographed under a microscope (PROVIS AX-UCDM, Olympus, USA) at 200× magnification. Five fields were counted per filter in each group and the experiment was conducted in triplicate.

Measurement of MMP-2 and TIMP-2 in culture supernatant

Fibroblast cell lines were treated with $79.5 \mu \mathrm{M}$ of NS-398 or $5 \mu \mathrm{M}$ of COX-2 AS for $24 \mathrm{~h}$. The amount of MMPs in the culture supernatant of fibroblasts was analyzed by
Fig. 1 Invasion activity of oral squamous cell carcinoma cell lines were examined. Both OSCC cells in contact with the supernatant of fibroblasts treated with either NS-398 or COX-2 AS showed lower invasiveness. $* P<0.01$ versus control
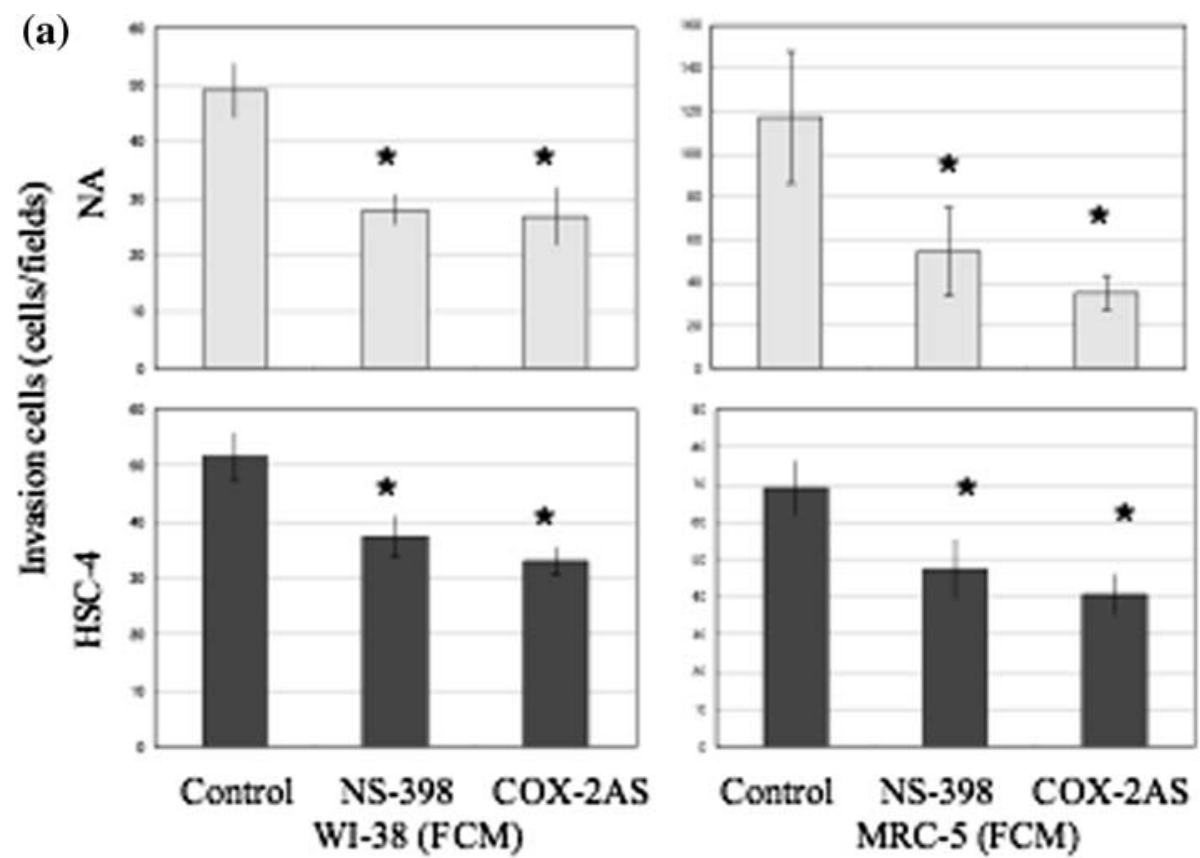

(b) W1-38 MRC-5 WI-38

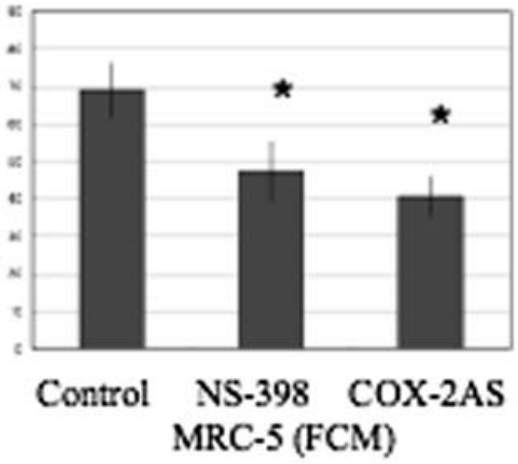

MRC-5
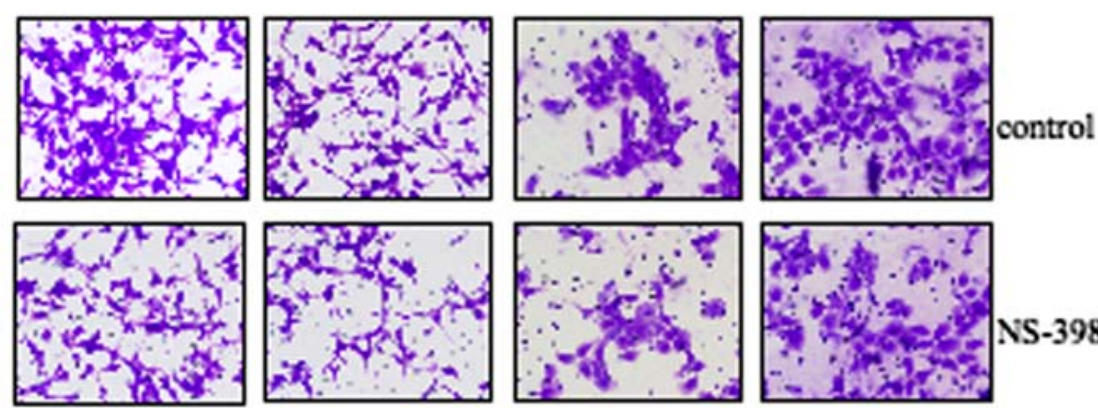



NA
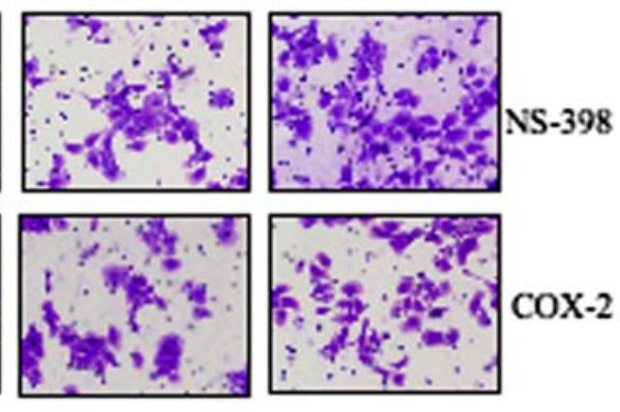
enzyme-linked immunosorbent assay (Matrix Metalloproteinase-2 and TIMP-2 human ELISA system, Amersham Pharmacia Biotech) according to the assay protocol. All measurements were made in triplicate.

Flow cytometric analysis

The OSCC cell lines were treated with $79.5 \mu \mathrm{M}$ of NS-398 or $5 \mu \mathrm{M}$ of COX-2 AS for $24 \mathrm{~h}$. For analysis of MT1-MMP expression, cells from each treatment group were harvested and labeled with CFS-conjugated anti-human MT1-MMP antibody for $1 \mathrm{~h}$. The cells were then analyzed by flow cytometry using the Becton Dickinson FACScalibur system. Control cells were stained with CFS-conjugated mouse IgG1.

\section{Results}

Effects of COX-2 inhibition on the cell viability of fibroblasts

We performed the MTT assay on fibroblast cells that were treated with either $79.5 \mu \mathrm{M}$ of NS-398 or $5 \mu \mathrm{M}$ of COX-2 AS for up to $48 \mathrm{~h}$ to assess the cytotoxicity caused by these reagents in the present study. As a result, these anti-COX-2 reagents had no significant effect on the viability of fibroblast cells (data not shown).

\section{Invasion assay}

To examine the effects of culture supernatant from fibroblast cell lines treated with NS-398 and COX-2 AS on the invasiveness of OSCC cells, we performed the Matrigel invasion assay. As shown in Fig. 1a, both OSCC cell lines in contact with the supernatant of fibroblasts treated with either NS-398 or COX-2 AS showed significantly lower invasiveness $(P<0.01)$. The OSCC cells that invaded the outer surface of the membrane were stained with crystal violet. Figure $1 \mathrm{~b}$ shows that the stained OSCC cells, contact with the supernatant of fibroblasts treated with either NS-398 or COX-2 AS, were less than control group.

Measurement of MMP-2 and TIMP-2 in culture supernatant of fibroblasts

To assess the effects of NS-398 or COX-2 AS on the secretion of MMP-2 and TIMP-2 into the culture supernatant of fibroblasts, we performed an enzyme-linked immunosorbent assay. As shown in Fig. 2, the amounts of MMP-2 and TIMP-2 in culture supernatant were significantly decreased by treatment with either NS-398 or COX-2 AS in both fibroblast cell lines.

Effects of COX-2 inhibition on the protein level of MMPs in fibroblasts

To evaluate the effects of these anti-COX-2 reagents on the protein expression of MMP-2 and TIMP-2 in WI-38 and MRC-5 fibroblast cell lines, we performed Western blot analysis. Western blot analysis revealed that MMP-2 and TIMP-2 proteins were constitutively expressed in both fibroblast cell lines and the amounts of these proteins were reduced by treatment with either NS-398 or COX-2 AS (Fig. 3).
Fig. 2 Effects of COX-2 inhibition on the secretion of matrix metalloproteinases from fibroblasts. MMP-2 and TIMP-2 in culture supernatant were significantly decreased by treatment with either NS-398 or COX-2 AS in both fibroblasts cell lines. Values are the mean \pm standard deviation $(S D)$ of triplicate determinations. $* P<0.01$, ** $P<0.05$ versus control

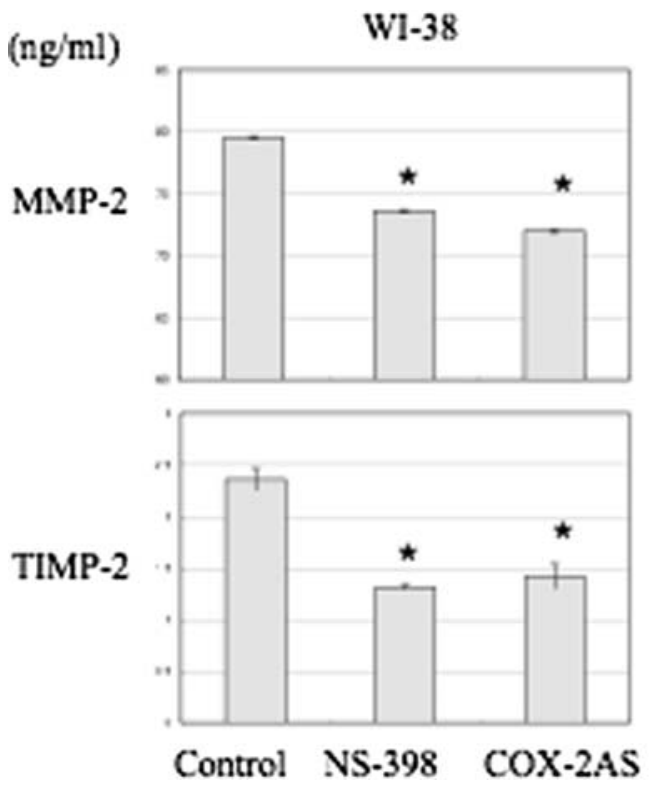

MRC-5
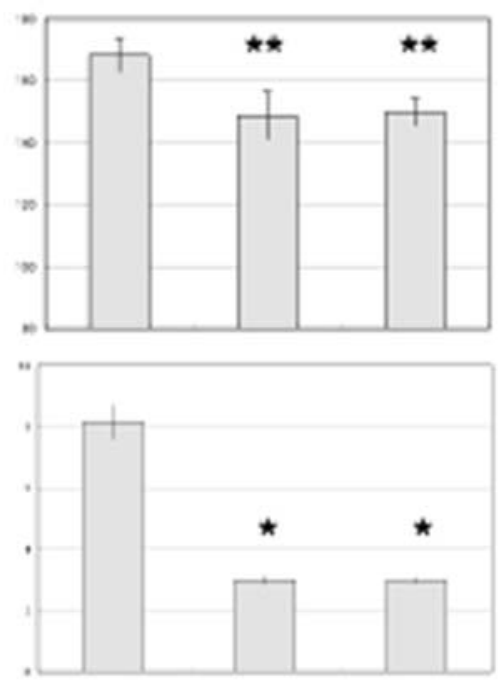

Control NS-398 COX-2AS 
Fig. 3 Western blot analysis of MMP-2 and TIMP-2 in

fibroblast cell lines. MMP-2 and TIMP-2 were constitutively expressed in both fibroblast cell lines and these proteins were reduced by treated with either NS-398 or COX-2 AS
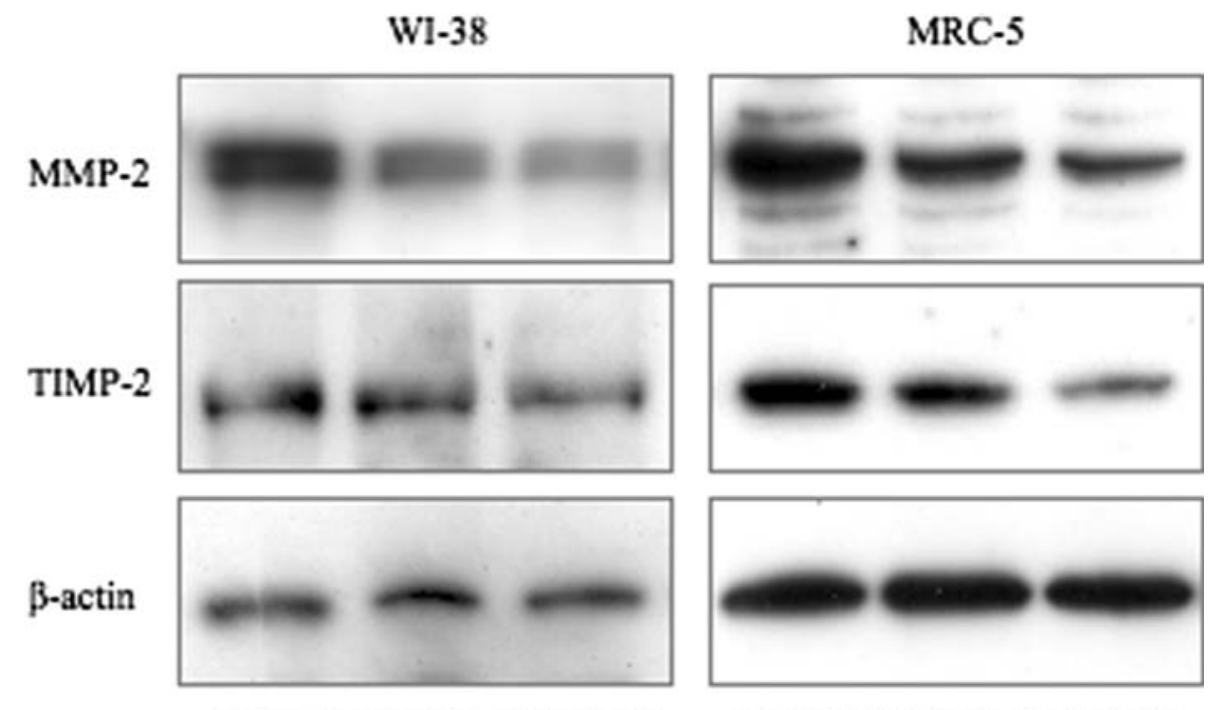

Control NS-398 COX-2AS

\section{Control NS-398 COX-2AS}

Flow cytometric analysis of MT1-MMP expression

To assess the effects of COX-2 inhibition on the expression of MT1-MMP on the surface of OSCC cells, NA and HSC4 cancer cell lines were treated with either NS-398 or COX-2 AS after 24-h incubation and the expression of
MT1-MMP was then evaluated by flow cytometry. Although MT1-MMP was constitutively expressed on the surface of NA cells, the expression of MT1-MMP was reduced by treatment with either NS-398 or COX-2 AS. Similar results were seen in HSC-4 cells treated with NS398 or COX-2 AS (Fig. 4).
Fig. 4 Expression of MT1MMP on the surface of oral squamous cell carcinoma cells. MT1-MMP was reduced by treatment with either NS-398 or COX-2 AS

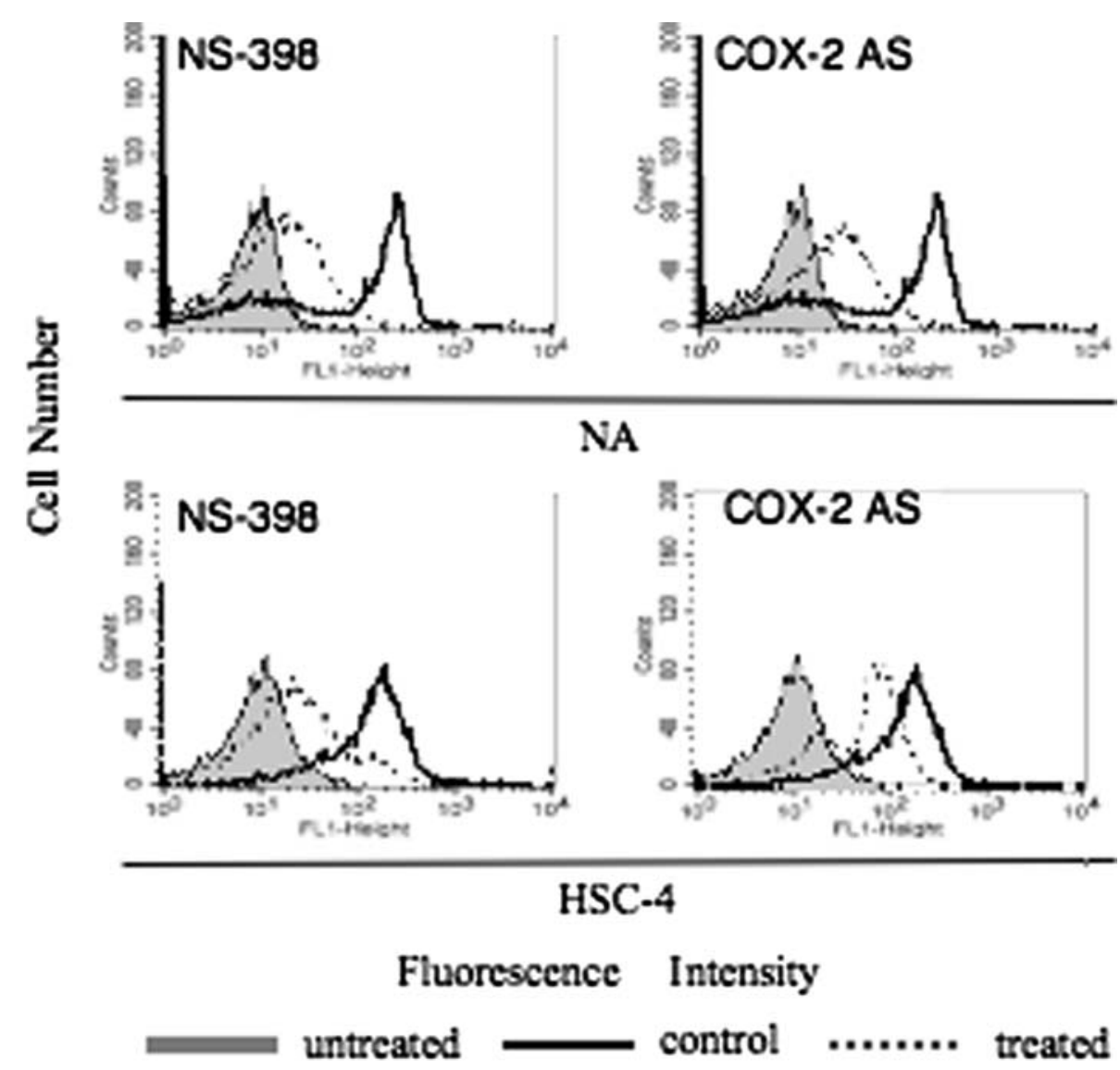




\section{Discussion}

Transcription of COX-2 is constitutively up-regulated in several malignancies including oral cancer [17]. Several studies have indicated that overexpression of COX-2 is associated with resistance to apoptosis, angiogenesis, decreased host immunity, and enhanced invasion and metastasis [18-21]. We previously reported that COX-2 is overexpressed in human OSCC cell lines NA and HSC-4 and that the proliferation of these cells was down-regulated by treatment with NS-398, a highly selective inhibitor of COX-2. Furthermore, we reported that the COX-2 inhibition suppressed the invasiveness of NA and HSC-4 cells via down-regulation of MMP-2 secreted by these cells and CD44 on the surface of the cells. However, many cancer studies have acknowledged the active roles that tumor stroma can play in carcinogenesis, focusing on the abnormal communication between the tumor cells and their microenvironment [22]. The stromal microenvironment has been reported to be associated with a multistep process including initiation, progression, and invasion [23-26]. In the present study, we examined the effect of invasion activity of OSCC cells cultured with supernatant from fibroblasts treated with either NS-398 or COX-2 AS. Our results indicated that the invasiveness of NA and HSC-4 cultured with supernatant from fibroblasts treated with either NS-398 or COX-2 AS was suppressed, as determined by the Matrigel invasion assay. To define the inhibitory effects of these reagents on the invasiveness of OSCC cells, we focused on the effects of these anti-COX-2 reagents on MMP expressions in fibroblast cell lines because it is well known that most MMPs play an important role at the cancer invasion front in vivo [27, 28]. In addition, it has also been reported that not only tumor cells but also normal peripheral cells such as stromal fibroblasts increase the expression of MMPs, which are available for the breakdown of the extracellular matrix to enhance tumor invasion [29]. Therefore, the behavior of MMPs in both cancer cells and stromal fibroblasts should be estimated.

Matrix metalloproteinases are a family of highly homologous extracellular zinc- and calcium-dependent endopeptidases with enzymatic activity against almost all protein components of the extracellular matrix. Based on protein domain structure and substrate specificity, MMPs can be divided into four subclasses: collagenases, gelatinases, stromelysins, and membrane-type MMPs [30]. We evaluated MMP-2 expression because the main component of the basement membrane is type IV collagen, which is degraded by collagenases, and several reports have indicated a correlation between increased MMP-2 expression and metastatic potential in various cancer cell lines [31-33].
Furthermore, Attiga et al. [34] reported the inhibition of MMP-2 and MMP-9 by COX-2 inhibitors in prostate cancer. As shown in the current study, both NS-398 and COX-2 AS suppress the secretion of MMP-2 into the culture supernatant as well as the expression of MMP-2 protein in fibroblast cells.

Among the MT-MMPs, MT1-MMP has been shown to be frequently expressed in migratory cells such as osteoclasts, endothelial cells, and invasive cancer cells [35-37]. MT1-MMP degrades collagen types I, II, and III, fibronectin, laminin 1 and 5, vitronectin, and aggrecan [38]. It also activates other MMPs such as proMMP-2 and proMMP-13 (procollagenase 3) [39]. Thus, the expression of MT1-MMP on the cell surface is thought to trigger multiple proteinase cascades. Therefore, we investigated the effects of COX-2 inhibition on the expression of MT1MMP. The expression of MT1-MMP on the cell surface of OSCC cells was dramatically suppressed by treatment with NS-398 or COX-2 AS.

Enzymatic activities of MMPs are controlled by TIMPs under physiological and pathological conditions [40]. The metastasis of malignant tumor cells is inhibited by exogenously administering or overexpressing TIMP-1 and TIMP-2 in vivo and in vitro [41-44]. TIMP-3 and TIMP-4 have also been reported to prevent tumor cell invasion and metastasis in vitro and in vivo [45, 46]. Furthermore, elevated expression of TIMPs is observed concomitant with augmenting the production of MMPs in various tumor tissues [29, 41], suggesting a host response to tumor invasion and metastasis in an effort to regulate the activity of MMPs for preventing extracellular matrix breakdown. In the current study, both NS-398 and COX-2 AS suppress the secretion of TIMP-2 into the culture supernatant as well as the expression of TIMP-2 protein in fibroblast cells.

Tumor-stromal cell contact provides a crucial signal for the progression of tumor invasiveness via soluble factors and/or membrane-anchored molecules. The MMPs protein is located in carcinoma cell membranes linked to MT1MMP and TIMP-2 complex. This complex is required for full local, pericellular MMP-2 activity in cancer tissue. MMP-2 is mainly synthesized in peritumoral fibroblasts rather than tumor cells in breast, colon, lung, skin, and head and neck cancers [47]. Numerous studies have now shown the induced expression of other MMPs in head and neck carcinomas produced both by tumor cells and surrounding stromal cells [24, 42, 48, 49].

The results shown in the present study confirm that COX-2 inhibition suppresses the invasiveness of OSCC cells cultured with supernatant from fibroblasts via downregulation of MMPs secreted by the fibroblasts. Genetic or pharmacological inhibition of COX-2 may therefore be a beneficial strategy in the treatment of OSCC. 
Open Access This article is distributed under the terms of the Creative Commons Attribution Noncommercial License which permits any noncommercial use, distribution, and reproduction in any medium, provided the original author(s) and source are credited.

\section{References}

1. Eberhart CE, Dubois RN (1995) Eicosanoids and the gastrointestinal tract. Gastroenterology 109(1):285-301. doi:10.1016/00165085(95)90296-1

2. Marnett LJ (1992) Aspirin and the potential role of prostaglandins in colon cancer. Cancer Res 52(20):5575-5589

3. Hosoi T, Takeda K, Konno K (1989) Synergism of prostaglandin E2 plus TNF in induction of differentiation of human monocytoid leukemic U-937 cells. Anticancer Res 9(3):615-618

4. Herschman HR (1996) Prostaglandin synthase 2. Biochim Biophys Acta 1299(1):125-140

5. Dubois RN, Abramson SB, Crofford L et al (1998) Cyclooxygenase in biology and disease. FASEB J 12(12):1063-1073

6. Williams CS, Smalley W, Dubois RN (1997) Aspirin use and potential mechanisms for colorectal cancer prevention. J Clin Investig 100(6):1325-1329. doi:10.1172/JCI119651

7. Gupta S, Srivastava M, Ahmad N et al (2000) Over-expression of cyclooxygenase-2 in human prostate adenocarcinoma. Prostate 42(1):73-78. doi:10.1002/(SICI)1097-0045(20000101)42:1<73:: AID-PROS9>3.0.CO;2-G

8. Wolff H, Saukkonen K, Anttila S et al (1998) Expression of cyclooxygenase-2 in human lung carcinoma. Cancer Res 58(22):4997-5001

9. Zimmermann KC, Sarbia M, Weber AA et al (1999) Cyclooxygenase-2 expression in human esophageal carcinoma. Cancer Res 59(1):198-204

10. Tucker ON, Dannenberg AJ, Yang EK et al (1999) Cyclooxygenase-2 expression is up-regulated in human pancreatic cancer. Cancer Res 59(5):987-990

11. Chan G, Boyle JO, Yang EK et al (1999) Cyclooxygenase-2 expression is up-regulated in squamous cell carcinoma of the head and neck. Cancer Res 59(5):991-994

12. Masferrer JL, Leahy KM, Koki AT et al (2000) Antiangiogenic and antitumor activities of cyclooxygenase- 2 inhibitors. Cancer Res 60(5):1306-1311

13. Uefuji K, Ichikura T, Mochizuki H (2000) Cyclooxygenase-2 expression is related to prostaglandin biosynthesis and angiogenesis in human gastric cancer. Clin Cancer Res 6(1):135-138

14. Sato H, Takino T, Okada Y et al (1994) A matrix metalloproteinase expressed on the surface of invasive tumour cells. Nature 370:61-65. doi:10.1038/370061a0

15. Sumitani K, Kamijo R, Toyoshima T et al (2001) Specific inhibition of cyclooxygenase- 2 results in inhibition of proliferation of oral cancer cell lines via suppression of prostaglandin E2 production. J Oral Pathol Med 30(1):41-47. doi:10.1034/j.16000714.2001.300107.x

16. Kinugasa Y, Hatori M et al (2004) Inhibition of cyclooxygenase-2 suppresses invasiveness of oral squamous cell carcinoma cell lines via down-regulation of matrix metalloproteinase-2 and CD44. Clin Exp Metastasis 21:737-745. doi:10.1007/s10585-005-1190-x

17. Tang DW, Lin SC, Chang KW et al (2003) Elevated expression of cyclooxygenase (COX)-2 in oral squamous cell carcinomaevidence for COX-2 induction by areca quid ingredients in oral keratinocytes. J Oral Pathol Med 32(9):522-529. doi:10.1034/ j.1600-0714.2003.00182.x

18. Tang X, Sun YJ, Half E et al (2002) Cyclooxygenase-2 overexpression inhibits death receptor 5 expression and confers resistance to tumor necrosis factor related apoptosis-inducing ligand-induced apoptosis in human colon cancer cells. Cancer Res 62(17):4903-4908

19. Leung WK, To KF, Go MY et al (2003) Cyclooxygenase-2 upregulates vascular endothelial growth factor expression and angiogenesis in human gastric carcinoma. Int $\mathbf{J}$ Oncol 23(5):1317-1322

20. Huang M, Stolona M, Sharma S et al (1998) Non-small cell lung cancer cyclooxygenase-2-dependent regulation of cytokine balance in lymphocytes and macrophages: up-regulation of interleukin 10 and down-regulation of interleukin 12 production. Cancer Res 58(6): 1208-1216

21. Abiru S, Nakao K, Ichikawa T et al (2002) Aspirin and NS-398 inhibit hepatocyte growth factor-induced invasiveness of human hepatoma cells. Hepatology (Baltimore) 35(5):1117-1124. doi: 10.1053/jhep.2002.32676

22. Tisty TD (2001) Stromal cells can contribute oncogenic signals. Semin Cancer Biol 11:97-104. doi:10.1006/scbi.2000.0361

23. Radisky D, Hagios C, Bissell MJ (2001) Tumors are unique organs defined by abnormal signaling and context. Semin Cancer Biol 11:87-95. doi:10.1006/scbi.2000.0360

24. Che AM, Jung TH, Choi JH et al (2006) Collagen-based coculture for invasive study on cancer cells-fibroblasts interaction. Biochem Biophys Res Commun 346:268-275. doi:10.1016/ j.bbrc.2006.05.111

25. Sympson CJ, Werb Z, Bissell MJ (1995) Mammary gland tumor formation in transgenic mice overexpressing stromelysin-1. Semin Cancer Biol 6:159-163. doi:10.1006/scbi.1995.0022

26. Sternlicht MD, Lochter A, Sympson CJ et al (1999) The stromal proteinase MMP3/Stromelysin-1 promotes mammary carcinogenesis. Cell 98:137-146. doi:10.1016/S0092-8674(00)81009-0

27. Hofmann UB, Westphal JR, Zendman AJ et al (2000) Expression and activation of matrix metalloproteinase-2 (MMP-2) and its colocalization with membrane-type matrix metalloproteinase 1 (MT1MMP) correlate with melanoma progression. J Pathol 191:245-256. doi:10.1002/1096-9896(2000)9999:9999<::AID-PATH632>3.0. CO;2-\#

28. Hofmann UB, Eggert AAO, Blass K et al (2003) Expression of matrix metalloproteinases in the microenvironment of spontaneous and experimental melanoma metastases reflects the requirements for tumor formation. Cancer Res 63(23):8221-8225

29. Westermarck J, Kähäri V-M (1999) Regulation of matrix metalloproteinase expression in tumor invasion. FASEB $\mathrm{J}$ 13:781-792

30. Chambers AF, Matrisian LM (1997) Changing views of the role of matrix metalloproteinases in metastasis. J Natl Cancer Inst 89(17):1260-1270. doi:10.1093/jnci/89.17.1260

31. Yang C, Zeisberg M, Lively JC et al (2003) Integrin alpha1beta1 and alpha2beta1 are the key regulators of hepatocarcinoma cell invasion across the fibrotic matrix microenvironment. Cancer Res 63(23):8312-8317

32. Robinson CM, Stone AM, Shields JD et al (2003) Functional significance of MMP-2 and MMP-9 expression by human malignant oral keratinocyte cell lines. Arch Oral Biol 48(11):779-786. doi:10.1016/S0003-9969(03)00172-9

33. Bernardo MM, Fridman R (2003) TIMP-2 (tissue inhibitor of metalloproteinase-2) regulates MMP-2 (matrix metalloproteinase-2) activity in the extracellular environment after pro-MMP-2 activation by MT1 (membrane type 1)-MMP. Biochem J 374:739-745. doi:10.1042/BJ20030557

34. Attiga FA, Fernandez PM, Weeraratna AT et al (2000) Inhibitors of prostaglandin synthesis inhibit human prostate tumor cell invasiveness and reduce the release of matrix metalloproteinases. Cancer Res 60(16):4629-4637

35. Sato T, n Ovejero M, Hou P et al (1997) Identification of the membrane-type matrix metalloproteinase MT1-MMP in osteoclasts. J Cell Sci 110(5):589-596 
36. Hiraoka N, Allen E, Apel IJ et al (1998) Matrix metalloproteinases regulate neovascularization by acting as pericellular fibrinolysins. Cell 95(3):365-377. doi:10.1016/S0092-8674(00)81768-7

37. Seiki M, Yana I (2003) Roles of pericellular proteolysis by membrane type-1 matrix metalloproteinase in cancer invasion and angiogenesis. Cancer Sci 94(7):569-574. doi:10.1111/j.13497006.2003.tb01484.x

38. Seiki M (2003) Membrane-type 1 matrix metalloproteinase: a key enzyme for tumor invasion. Cancer Lett 194(1):1-11. doi:10.1016/ S0304-3835(02)00699-7

39. Knauper V, Will H, Lopez-Otin C et al (1996) Cellular mechanisms for human procollagenase-3 (MMP-13) activation. Evidence that MT1-MMP (MMP-14) and gelatinase (MMP-2) are able to generate active enzyme. J Biochem 271(29):17124-17131

40. Brew K, Kinakarpandian K, Nagase H (2000) Tissue inhibitors of metalloproteinases: evolution, structure, and function. Biochim Biophys Acta 1477:267-283

41. Stetler-Stevenson WG, Aznavoorian S, Liotta LA (1993) Tumor cell interactions with the extracellular matrix during invasion and metastasis. Annu Rev Cell Biol 9:541-573. doi:10.1146/annurev. cb.09.110193.002545

42. Sato T, Iwai M, Sakai T et al (1999) Enhancement of membranetype 1-matrix metalloproteinase (MT1-MMP) production and sequential activation of progelatinase $\mathrm{A}$ on human squamous carcinoma cells co-cultured with human dermal fibroblasts. Br J Cancer 80:1137-1143. doi:10.1038/sj.bjc.6690477

43. Noël A, Hajitou A, L'Hoir C et al (1998) Inhibition of stromal matrix metalloproteinases: effects on breast-tumor promotion by fibroblasts. Int J Cancer 76:267-273. doi:10.1002/(SICI)10970215(19980413)76:2<267::AID-IJC15>3.0.CO;2-9

44. Kruger A, Sanchez-Sweatman OH, Martin DC et al (1998) Host TIMP-1 overexpression confers resistance to experimental brain metastasis of a fibrosarcoma cell line. Oncogene 16:2419-2423. doi:10.1038/sj.onc.1201774

45. Wang M, Liu YE, Greene S et al (1997) Inhibition of tumor growth and metastasis of human breast cancer cells transfected with tissue inhibitor of metalloproteinase 4. Oncogene 14:27672774. doi:10.1038/sj.onc. 1201245

46. Baker AH, George SJ, Zaltsman AB, Murphy G, Newby AC (1999) Inhibition of invasion and induction of apoptotic cell death of cancer cell lines by overexpression of TIMP-3. Br J Cancer 79:1347-1355. doi:10.1038/sj.bjc.6690217

47. Basset P, Bellocq JP, Wolf C et al (1990) A novel metalloproteinase gene specifically expressed in stromal cells of breast carcinomas. Nature 348:699-704. doi:10.1038/348699a0

48. Sorsa T, Tjaderhane L, Salo T (2004) Matrix metalloproteinases (MMPs) in oral diseases. Oral Dis 10:311-318. doi:10.1111/ j.1601-0825.2004.01038.x

49. Okada A, Bellocq JP, Rouyer N et al (1995) Membrane-type matrix metalloproteinase (MT-MMP) gene is expressed in stromal cells of human colon, breast, and head and neck carcinomas. Proc Natl Acad Sci USA 92:2730-2734. doi:10.1073/pnas.92. 7.2730 